\title{
Six-Month Intravascular Ultrasound Follow-up of Coronary Bifurcation Lesions Treated With Rapamycin-Eluting Stents: Technical Considerations
}

\author{
Manuel Pan, ${ }^{a}$ José Suárez de Lezo, ${ }^{a}$ Alfonso Medina, ${ }^{b}$ Miguel Romero, ${ }^{a}$ Antonio Delgado, ${ }^{b}$ \\ José Segura, ${ }^{a}$ Soledad Ojeda, ${ }^{a}$ Djordje Pavlovic, ${ }^{a}$ Javier Ariza, ${ }^{a}$ Jaime Fernández-Dueñas, ${ }^{a}$ \\ Juan Herrador, ${ }^{a}$ and Isabel Ureña ${ }^{a}$
}

\begin{abstract}
aServicio de Cardiología, Hospital Reina Sofía, Universidad de Córdoba, Córdoba, Spain.
'Servicio de Cardiología, Hospital Doctor Negrín, Universidad de las Palmas, Las Palmas de Gran Canaria, Spain.
\end{abstract}

\begin{abstract}
Introduction and objectives. In vitro studies show that stents deform when dilated laterally to access a side branch. This phenomenon may be avoided by use of a kissing balloon at the end of the procedure. However, to date, no in vivo data are available. Our objectives were to investigate the main vessel stent using intravascular ultrasound (IVUS) at six-month follow-up in 55 patients with bifurcation lesions treated using rapamycin-eluting stents and to examine the effect of technical factors.
\end{abstract}

Patients and method. All patients were treated using provisional or T stents. At 6 months, IVUS measurements were made in the main vessel at both proximal and distal ends of the stent, in reference segments, immediately below the side branch ostium, and at the points where the lumen was smallest and where stent expansion was greatest.

Results. The lumen area immediately below the side branch ostium was significantly smaller than that at the point of maximum stent expansion (6.7 [1.8] vs 5.1 [1.3] $\left.\mathrm{mm}^{2} ; P<.05\right)$. Underexpansion was not influenced by use of a kissing balloon (stent area immediately under the side branch ostium: 5.5 [0.9] vs 5.6 [1.6] $\mathrm{mm}^{2} ; P=\mathrm{NS}$ ) and only one patient experienced restenosis at this point. The lumen areas at the proximal and distal edges of the stent were almost identical in patients who did or did not undergo balloon dilation beyond the ends of the stent.

Conclusions. Stent underexpansion below the side branch ostium was frequently found following provisional or T stenting of bifurcation lesions. This minor stent deformity was not prevented by use of a kissing balloon nor by any specific side branch treatment and had no significant impact on the restenosis rate.

Key words: Rapamycin-eluting stent. Bifurcation lesion. Intravascular ultrasound.

\section{SEE EDITORIAL ON PAGES 1261-5}

Correspondence: Dr. M. Pan

AININCAR.

Apartado Postal 2.031. 14080 Córdoba. España.

E-mail: grupo_corpal@arrakis.es

Received March 21, 2005

Accepted for publication July 4, 2005
Ecografía intracoronaria durante el seguimiento en la valoración de stents liberadores de rapamicina para el tratamiento de las lesiones en bifurcación: implicaciones técnicas

Introducción y objetivos. Los estudios in vitro han mostrado que el stent se deforma cuando se dilata lateralmente para acceder a un ramo colateral. Así, se han propuesto algunas técnicas para evitar este fenómeno; sin embargo, no hay información in vivo disponible. El objetivo es investigar los hallazgos ultrasónicos a los 6 meses en 55 pacientes con lesiones localizadas en bifurcación tratados mediante stents de rapamicina.

Pacientes y método. Todos los pacientes fueron tratados con stent en el vaso principal y stent o dilatación con balón en el ramo colateral. Se analizaron los bordes del stent, los segmentos de referencia, el diámetro mínimo de la luz, el punto inmediatamente tras la salida del ramo colateral y el stent en el punto de máxima expansión.

Resultados. El área de la luz en el punto inmediatamente tras la salida del ramo colateral fue significativamente más pequeña que en el punto de máxima expansión $\left(6,7 \pm 1,8\right.$ frente a 5,1 $\left.\pm 1,3 \mathrm{~mm}^{2} ; \mathrm{p}<0,05\right)$. Esta inexpansión del stent no estuvo influida por el uso del inflado simultáneo de balones al final del procedimiento (área del stent inmediatamente bajo el origen del ramo colateral, 5,5 $\pm 0,9$ frente a 5,6 $\pm 1,6 \mathrm{~mm}^{2} ; \mathrm{p}=\mathrm{NS}$ ). El área de la luz en los bordes fue prácticamente idéntica entre pacientes con y sin inflado de balón más allá de los límites del stent.

Conclusiones. Cierto grado de inexpansión del stent inmediatamente después de la salida del ramo colateral fue un hallazgo frecuente en pacientes con bifurcaciones tratados con stents en el ramo principal y stent provisional en el ramo colateral. Esta deformidad no fue prevenida por variables técnicas y no tuvo un impacto significativo en la incidencia de reestenosis.

Palabras clave: Stent de rapamicina. Lesiones coronarias en bifurcación. Ecografía intracoronaria. 


\section{INTRODUCTION}

During the percutaneous treatment of a bifurcation lesion, the main vessel stent is necessarily deformed when the side branch (SB) is dilated through the stent struts. Bench studies have been performed ${ }^{1-3}$ and certain theoretical considerations may be drawn from them. However, there are no in vivo follow-up studies that focus on the technical strategies that might preserve original main vessel stent geometry, or on the impact the degree of this stent deformation may have on late patient outcome. The purpose of this study is to investigate the 6-month intravascular ultrasound (IVUS) appearance of the parent vessel stent in patients with bifurcation lesions treated in the era of drug-eluting stents as well as the influence of technical factors on IVUS parameters.

\section{PATIENTS AND METHOD}

\section{Patients}

Our series comprises 55 patients with bifurcation lesions treated by rapamycin-eluting stents (RES) between June 2002 and June 2004 who had 6 month angiographic and ultrasonic re-evaluation. All patients fulfilled the following inclusion criteria: 1 ) lesion located in a major bifurcation point regardless of morphology and angulation; 2) main vessel $>2.5 \mathrm{~mm}$ diameter; 3) $\mathrm{SB} \geq 2.25 \mathrm{~mm}$ diameter; 4) significant stenosis in both main vessel and SB origin. Patients with diffuse SB lesions were excluded. Written informed consent was obtained from all patients.

\section{Procedure}

The technique of RES implantation has been described previously. ${ }^{4,5}$ Balloon dilation of the SB or of the both vessels was performed first, followed by RES deployment in the parent vessel. The SB was then re-wired and balloon dilation of the ostium was repeated across the metallic structure of the stent. Whether to stent the SB origin or not was dictated by a randomization process between June 2002 and April 2003 , and according to the criteria of the operator in patients treated between June 2003 and June 2004, so all our patients were treated with provisional or $\mathrm{T}$ stenting. The decision to perform final kissing balloon or balloon dilation beyond the stent limits was at the discretion of the operator. The same balloon used for stent deployment at the main vessel was also used for the final kissing balloon inflation with a second balloon of the same diameter as the reference SB. The inflation pressure was lower than for stent deployment (6-12 atmospheres). The balloon/artery ratio for each distal branch was close to 1 . In the hemodynamic laboratory, patients received a bolus of $1-2 \mathrm{mg} / \mathrm{kg}$ of intravenous unfractionated heparin continuing with low-molecularweight heparin $\left(\right.$ Fragmin $\left.^{\circledR}\right) 10000 \mathrm{IU}$ anti-Xa/day, ticlopidine $500 \mathrm{mg} / \mathrm{day}$, and aspirin $150 \mathrm{mg} /$ day for the first month. After this initial regimen, patients continued with clopidogrel and aspirin for 1 year. Protamine was administered at the end of the procedure allowing immediate removal of the femoral sheath. We used the CAAS II version 4.1.1 (Pie Medical Imaging, Maastricht, Netherlands) for quantitative coronary angiography, with the dye-filled catheter as a reference. Quantitative parameters were obtained at baseline condition, immediately post-procedure and at follow-up.

\section{Follow-up Study}

Patients were followed up closely by telephone and further cardiac catheterization was scheduled at 6month evaluation or earlier in the presence of symptoms. Quantitative coronary angiography was performed at follow-up and quantitative measurements were obtained in the same selected view. Restenosis was defined as a $>50 \%$ stenosis at follow-up.

All IVUS studies were obtained after a bolus (450 $\mu \mathrm{g}$ ) of intracoronary nitroglycerin. A 64-element, 3.5 $\mathrm{F}$ monorail catheter $\left(\right.$ EndoSonics $\left.^{\circledR}\right)$ was used in every study. Intrastent ultrasound-measurements were obtained in the main vessel at the edges, at the minimal lumen diameter, immediately under the SB origin and at the maximal stent diameter. Proximal and distal references were examined at $1 \mathrm{~cm}$ from the stent borders. The following measurements were obtained at each site: external elastic lamina area, stent area and lumen area.

\section{Statistics}

Data are expressed as mean \pm standard deviation. A Student-Fisher unpaired $t$ test was used to compare quantitative data from different groups of patients. Linear correlation between balloon inflation pressures and IVUS parameters was assessed with the Pearson correlation coefficient $(r)$. A value of $P<.05$ was considered statistically significant.

\section{RESULTS}

\section{Baseline and Procedural Data}

Baseline clinical data are shown in Table 1. Most of patients presented an unstable clinical condition at hospital admission and 26 were diabetics. The bifurcation site was most frequently located at the left anterior descending artery/diagonal branch. The angiographic and procedural characteristics are summarized in Table 2 . The use of platelet glycoprotein IIb/IIIa inhibitors at the discretion of the researchers was used in 53\% of the patients. 
TABLE 1: Baseline Clinical Data $(\mathbf{n}=55)$

\begin{tabular}{lc}
\hline Age, year & $59 \pm 11$ \\
Male, $\%$ & $47(85 \%)$ \\
Risk factors & \\
$\quad$ Diabetes & $26(47 \%)$ \\
$\quad$ Hypertension & $26(47 \%)$ \\
$\quad$ Hyperlipemia & $27(49 \%)$ \\
$\quad$ Current smoking & $22(40 \%)$ \\
Previous myocardial infarction & $16(29 \%)$ \\
Stable angina & $4(7 \%)$ \\
Unstable angina & $51(93 \%)$ \\
\hline
\end{tabular}

\section{In-Hospital and 1-Month Outcome}

Angiographic success was obtained in all patients. One patient developed a non Q-wave myocardial infarction according to the immediate post-procedure serial creatine kinase determinations. The post procedure peak of creatine kinase was $102 \pm 127$ IU/L. At the main vessel, the angiographic minimal lumen diameter increased after the procedure from $0.81 \pm 0.5$ $\mathrm{mm}$ to $2.71 \pm 0.4 \mathrm{~mm}$, while at the side branch, the minimal lumen diameter changed from $0.87 \pm 0.4 \mathrm{~mm}$ to $1.96 \pm 0.4 \mathrm{~mm}$.

\section{Clinical and Angiographic Follow-up}

The mean follow-up period was $11 \pm 3$ months. The 6-month angiographic re-evaluation revealed a reduction in minimal lumen diameter at the main vessel stent from $2.71 \pm 0.4 \mathrm{~mm}$ to $2.44 \pm 0.5 \mathrm{~mm}$, and at the level of the side branch from $1.96 \pm 0.4 \mathrm{~mm}$ to $1.7 \pm 0.4 \mathrm{~mm}$. Two patients developed restenosis at the main vessel stent and one at the SB origin. The site of restenosis was at the body of the stent distally to the bifurcation point in one patient (Figure 1) and immediately under the side branch origin in the other (Figure 2). The patient with restenosis at the SB had previously been treated with stents in both branches and final kissing balloon inflation. Repeat target lesion revascularization was required in the 2 patients with restenosis at the main vessel, while the patient with SB restenosis was followed by medical treatment. Remote site revascularization of a non bifurcated lesion treated with bare metal stents occurred at 6 months in 2 patients. No additional major adverse cardiac events were observed at follow-up in the remaining 51 patients.

\section{Six Months IVUS}

Table 3 summarizes the 6-month follow-up IVUS findings at different sites of the parent vessel stent. A
TABLE 2. Angiographic and Procedural Data

\begin{tabular}{lr}
\hline Angiographic & \\
Ejection fraction & $61 \pm 13$ \\
Treated bifurcation & \\
$\quad$ LAD-Cx & $7(13 \%)$ \\
LAD-D1 & $33(60 \%)$ \\
CX-OM & $11(20 \%)$ \\
RCA-PDA & $4(7 \%)$ \\
Main vessel & \\
$\quad$ Reference diameter, mm & $3.1 \pm 0.4$ \\
$\%$ stenosis pre & $74 \pm 15$ \\
$\%$ stenosis post & $11 \pm 8$ \\
$\quad \%$ stenosis follow & $19=17$ \\
Side branch & \\
$\quad$ Reference diameter, mm & $2.4 \pm 0.3$ \\
$\%$ stenosis pre & $62 \pm 16$ \\
\% stenosis post & $17 \pm 11$ \\
\% stenosis follow & $24 \pm 16$ \\
Procedural & \\
Mean deployment pressure, atm & $14 \pm 2$ \\
Mean vessel stent diameter, mm & $3 \pm 0.34$ \\
Mean vessel stent length, mm & $23 \pm 11$ \\
Proximal geographic miss & $9(16 \%)$ \\
Distal geographic miss & $16(29 \%)$ \\
Abciximab & $29(53 \%)$ \\
Final kissing balloon & $19(34 \%)$ \\
Side branch stent & $16(29 \%)$ \\
Remote site intervention & $33(60 \%)$ \\
\hline
\end{tabular}

${ }^{*} \mathrm{Cx}$ indicates circumflex; D1, diagonal branch; LAD, left anterior descending artery; OM, obtuse marginal; PDA, posterior descending artery; RCA, right coronary artery.

small difference between the stent and lumen area was observed as a consequence of a reduced neointimal proliferation. The mean stent area along the stented bifurcation was not uniform. So, the stent and luminal areas immediately under the SB origin were significantly smaller than at maximal stent expansion $\left(7.0 \pm 2.1\right.$ and $6.7 \pm 1.8 \mathrm{~mm}^{2}$ vs $5.5 \pm 1.4$ vs $5.1 \pm 1.3 \mathrm{~mm}^{2} ; P<.05$ ) (Figure 3 and 4 ). The influence of kissing balloon on this stent deformation and 6 month IVUS parameters are summarized in Table 4. As can be seen there were no significant differences between the proximal and distal references and border measurements. A small but significant difference appeared in the stent area at maximal lumen between patients with and without kissing inflation as a result of double balloon inflation in the proximal part of the stent (Figure 5). However, in terms of lumen or stent areas there were no differences at the site of the stent immediately under the side branch (Table 4 and Figure 6). IVUS measurements were similar between patients with or without SB stenting (Table 5). The balloon/artery ratio at the main vessel did not influence the lumen or stent areas at the point immediately under the SB origin or at minimal lumen diameter. The following 
Figure 1. Bifurcation lesions at left anterior descending artery-diagonal branch treated by stenting of a long segment at the main vessel and balloon dilation of diagonal branch. At follow-up 2 sites of severe intra-stent restenosis were seen at the body of the stent but outside the bifurcation point (square)

Figure 2. Patient with a bifurcation lesion treated by main vessel stenting and balloon dilation of side branch. At 6 month re-evaluation, focal restenosis developed at the stent immediately under the side branch origin. Stent underexpansion as well as neointimal proliferation can be observed in the IVUS study.
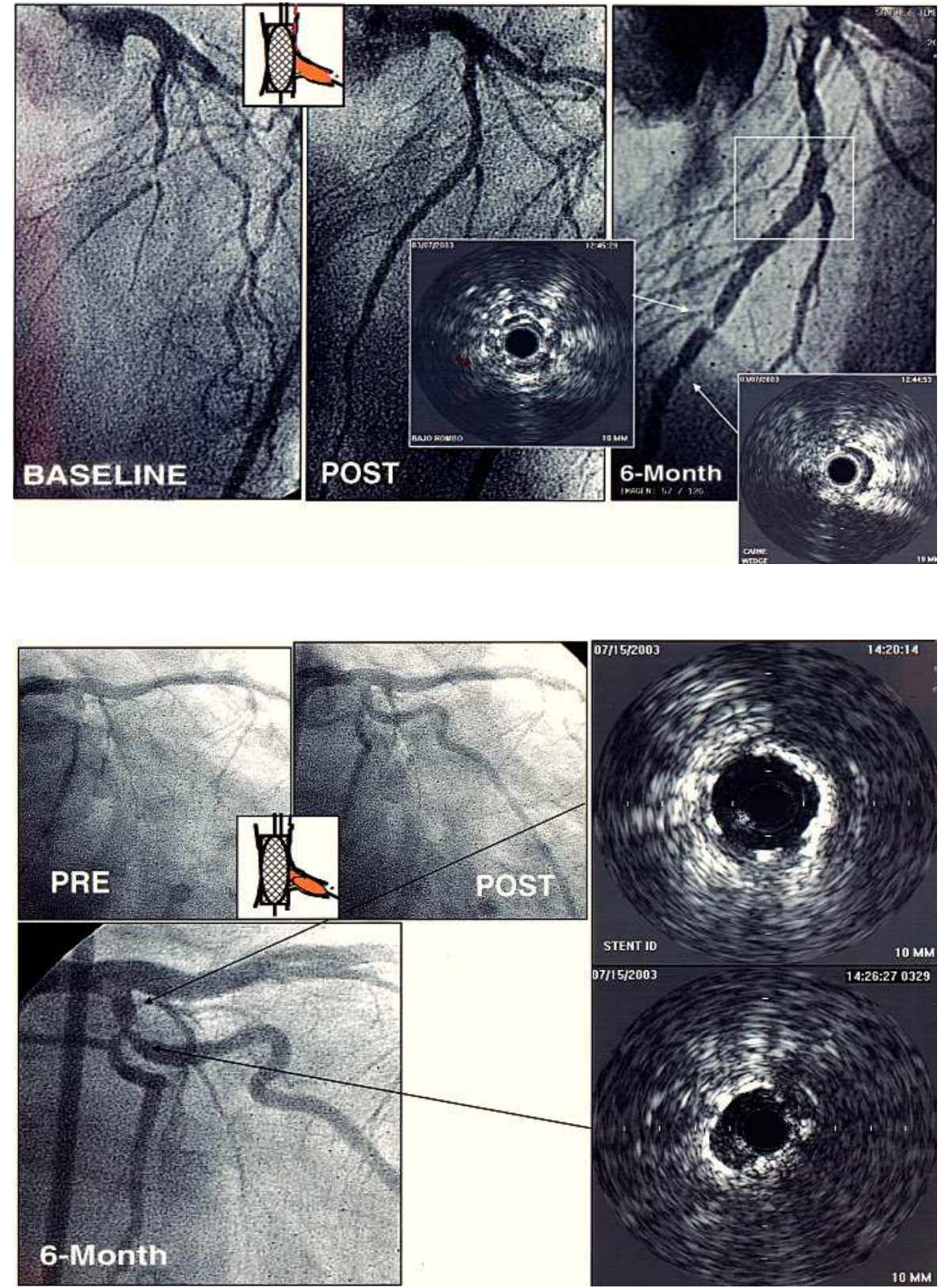

IVUS measurements were taken in patients with a balloon/artery ratio $\geq 1 \quad(n=31)$ as compared with those with balloon/artery ratio $<1(n=24): 1)$ stent area at minimal lumen diameter $5.0 \pm 1.6$ versus $5.0 \pm 1.1 \mathrm{~mm}^{2}$

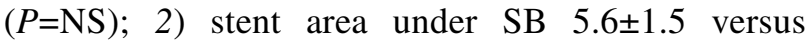
$5.5 \pm 1.2 \mathrm{~mm}^{2}(P=\mathrm{NS})$; 3) lumen area at minimal lumen diameter $4.5 \pm 1.5$ versus $4.6 \pm 1.1 \mathrm{~mm}^{2}(P=\mathrm{NS})$; and 4) lumen area under SB $5.1 \pm 1.4$ versus $5.0 \pm 1.2$ $\mathrm{mm}^{2}(P=\mathrm{NS})$. There was no correlation with inflation pressures during stent implantation and stent underexpansion. The correlation coefficients between inflation pressure and IVUS parameters were as follows: 1) stent area at minimal lumen diameter, $r=0.18 \quad(P=\mathrm{NS})$; 2) stent area under $\mathrm{SB}, \mathrm{r}=0.12$ $(P=\mathrm{NS})$; 3) lumen area at minimal lumen diameter,
$r=0.21(\mathrm{P}=\mathrm{NS})$; and 4) lumen area under $\mathrm{SB}, r=0.13$ $(P=\mathrm{NS})$. The relationships between ageographic miss and the related 6-month IVUS parameters are summarized in Table 6 . The proximal and distal lumen areas at the level of the border were almost identical in patients with or without balloon dilation beyond the stent limits. Furthermore none of our patients developed restenosis at stent borders.

\section{DISCUSSION}

Late IVUS findings after successful drug elutingstent implantation has been recently reported in non bifurcated lesions and complex lesions. ${ }^{6-10}$ These studies have demonstrated the efficacy of drug eluting- 


\section{TABLE 3. Intravascular Ultrasound at 6-Month} Follow-up*

\begin{tabular}{|c|c|}
\hline \multicolumn{2}{|l|}{ Proximal reference } \\
\hline EEL area, mm² & $18.1 \pm 7.0$ \\
\hline Lumen area, mm² & $10.5 \pm 5.5$ \\
\hline \multicolumn{2}{|l|}{ Proximal edge } \\
\hline EEL area & $18.8 \pm 6.7$ \\
\hline Lumen area & $8.7 \pm 4.2$ \\
\hline \multicolumn{2}{|c|}{ Maximal lumen diameter } \\
\hline EEL area & $18.8 \pm 4.8$ \\
\hline Stent area, $\mathrm{mm}^{2}$ & $7.0 \pm 2.1$ \\
\hline Lumen area, mm² & $6.7 \pm 1.8$ \\
\hline \multicolumn{2}{|c|}{ Minimal lumen diameter } \\
\hline EEL area & $15.5 \pm 5.7$ \\
\hline Stent area, mm² & $5.0 \pm 1.6$ \\
\hline Lumen area, mm² & $4.5 \pm 1.3$ \\
\hline \multicolumn{2}{|c|}{ Under side branch origin } \\
\hline EEL area & $16.6 \pm 4.2$ \\
\hline Stent area, $\mathrm{mm}^{2}$ & $5.5 \pm 1.4$ \\
\hline Lumen area, mm² & $5.1 \pm 1.3$ \\
\hline \multicolumn{2}{|l|}{ Distal edge } \\
\hline EEL area, mm² & $12.3 \pm 5.3$ \\
\hline Lumen area, mm² & $6.7 \pm 2.7$ \\
\hline \multicolumn{2}{|l|}{ Distal reference } \\
\hline EEL area, $\mathrm{mm}^{2}$ & $11.3 \pm 5.4$ \\
\hline Lumen area, $\mathrm{mm}^{2}$ & $6.5 \pm 2.6$ \\
\hline
\end{tabular}

${ }^{\star}$ EEL indicateds external elastic laminae.

stenting in inhibiting neointimal proliferation in de novo and in-stent restenosis lesions. Contrary to barestent treatment, ${ }^{11}$ drug-eluting stenting does not seem to need aggressive stent expansion to obtain late success. However some authors have suggested that stent underexpansion immediately after the procedure
TABLE 4. Influence of Kissing Balloon Inflation in 6-Month IVUS Results*

\begin{tabular}{|c|c|c|c|}
\hline & $\begin{array}{c}\text { Yes, } \\
(n=19)\end{array}$ & $\begin{array}{c}\text { Non, } \\
(n=36)\end{array}$ & $P$ \\
\hline \multicolumn{4}{|l|}{ Proximal reference } \\
\hline EEL area, $\mathrm{mm}^{2}$ & $18.4 \pm 6.7$ & $18.0 \pm 7.3$ & NS \\
\hline Lumen area, mm² & $11.7 \pm 4.5$ & $9.8 \pm 6.1$ & NS \\
\hline \multicolumn{4}{|l|}{ Proximal edge } \\
\hline EEL area & $18.9 \pm 5.5$ & $18.9 \pm 7.4$ & NS \\
\hline Lumen area & $9.3 \pm 3.6$ & $8.6 \pm 4.6$ & NS \\
\hline \multicolumn{4}{|c|}{ Maximal lumen diameter } \\
\hline EEL area, $\mathrm{mm}^{2}$ & $19.1 \pm 3.9$ & $18.6 \pm 5.3$ & NS \\
\hline Stent area, $\mathrm{mm}^{2}$ & $7.8 \pm 1.8$ & $6.8 \pm 1.7$ & $<.05$ \\
\hline Lumen area, mm² & $7.1 \pm 1.9$ & $6.5 \pm 1.8$ & NS \\
\hline \multicolumn{4}{|c|}{ Minimal lumen diameter } \\
\hline EEL area, $\mathrm{mm}^{2}$ & $16.8 \pm 4.6$ & $14.9 \pm 6.2$ & ns \\
\hline Stent area, $\mathrm{mm}^{2}$ & $5.3 \pm 1.2$ & $4.9 \pm 1.7$ & NS \\
\hline Lumen area, mm² & $4.7 \pm 1.0$ & $4.5 \pm 1.4$ & ns \\
\hline \multicolumn{4}{|c|}{ Under side branch origin } \\
\hline EEL area, $\mathrm{mm}^{2}$ & $17.2 \pm 4.3$ & $16.3 \pm 4.2$ & NS \\
\hline Stent area, $\mathrm{mm}^{2}$ & $5.5 \pm 0.9$ & $5.6 \pm 1.6$ & NS \\
\hline Lumen area, mm² & $5.1 \pm 0.9$ & $5.2 \pm 1.4$ & NS \\
\hline \multicolumn{4}{|l|}{ Distal edge } \\
\hline $\mathrm{EEL}$ area, $\mathrm{mm}^{2}$ & $12.4 \pm 4.5$ & $12.3 \pm 5.8$ & NS \\
\hline Lumen area, mm² & $6.6 \pm 2.0$ & $6.8 \pm 3.1$ & NS \\
\hline \multicolumn{4}{|l|}{ Distal reference } \\
\hline $\mathrm{EEL}$ area, $\mathrm{mm}^{2}$ & $11.4 \pm 4.6$ & $11.3 \pm 5.9$ & NS \\
\hline Lumen area, mm² & $6.7 \pm 2.3$ & $6.4 \pm 2.8$ & NS \\
\hline
\end{tabular}

${ }^{\star}$ EEL indicates external elastic laminae.

was associated with a higher restenosis rate in certain coronary lesion subsets. ${ }^{12}$

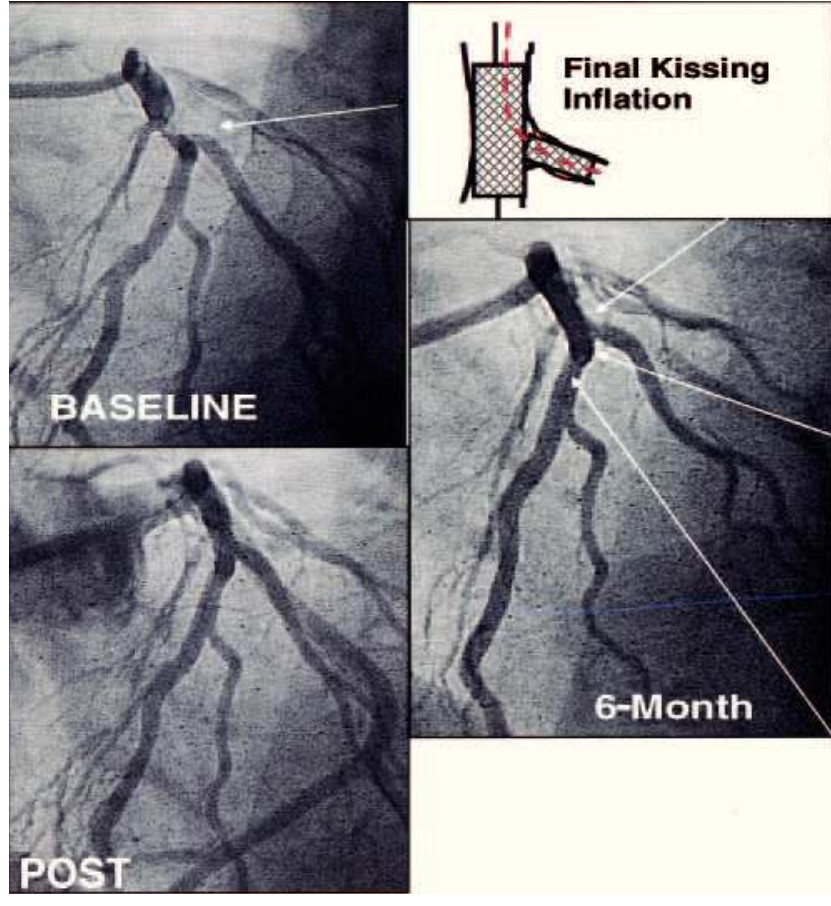

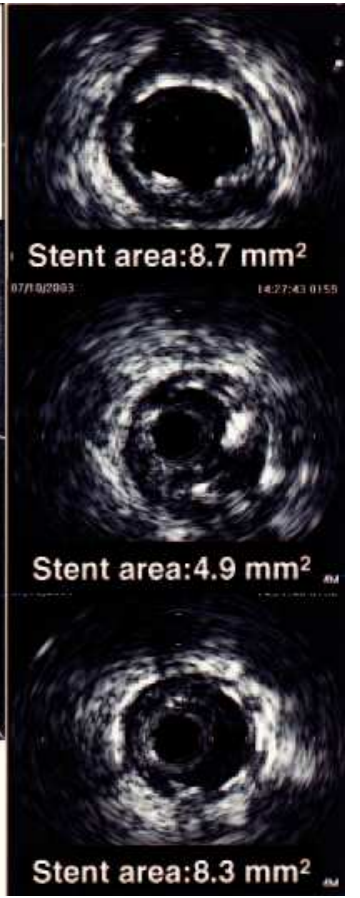

Figure 3. Bifurcation lesion at left anterior descending artery-diagonal branch, treated by stenting both vessels. Final kissing inflation was used and a significant main vessel stent underexpansion can be observed immediately under the side branch origin, compared with proximal or distal main vessel stent sites. 
Figure 4. Bifurcation lesion at left main treated by stenting of the left main-left anterior descending artery and balloon dilation of the circumflex origin. The IVUS immediately under the circumflex origin shows some degree of stent underexpansion, however, the six-month angiographic follow-up study shows an excellent result on the entire bifurcation.

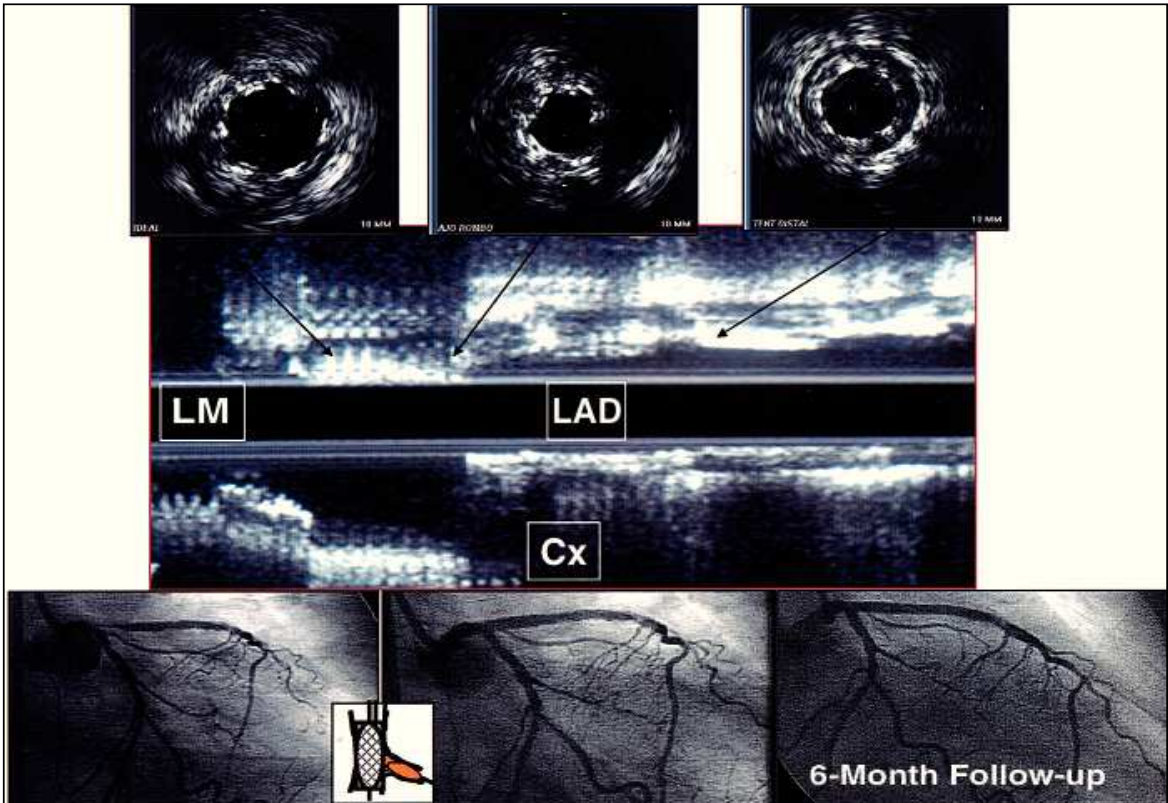

\section{Main Vessel Stent Deformation in Bifurcated Lesions}

In vitro studies have revealed stent deformation when opening struts to dilate a side branch. ${ }^{1-3}$ Final kissingballoon has been proposed to avoid this phenomenon, based on these studies. However, there is no in vivo information as yet available. Our study suggests that some degree of stent underexpansion under the side branch origin is a frequent finding after RES treatment of bifurcation lesions. This stent deformity is not prevented by kissing balloon inflation (Table 4) or by the type of SB treatment (Table 5). The lack of plaque shifting in bench studies may also account for the disagreement between our findings and the in vitro studies. An aggressive dilation of the SB is not needed in these experimental models. On the other hand, during the experimental studies the researcher may alternatively inflate the balloons with more or less pressure to obtain adequate stent geometry. In vivo, few balloon inflations are performed by operators without continuous monitoring of stent deformity. Although this deformation may be responsible for an increase in restenosis, our findings do not support this theory. Thus, only 1 patient developed restenosis under the side branch origin (Figure 2). As can be seen in this figure, beside the stent deformation, an associated neointimal proliferation caused a severe focal restenosis. Our findings are consistent with other angiographic followup studies ${ }^{13}$ that also found the side branch origin to be the most frequent site for restenosis, while the main vessel stent showed a low restenosis rate.
Figure 5. Bifurcation lesion at the left anterior descending artery-diagonal branch, treated by stenting of both vessels. The kissing balloon inflation gave a high proximal stent area, but the point immediately under the diagonal origin shows a reduction in stent area as compared with proximal or distal stent segments.
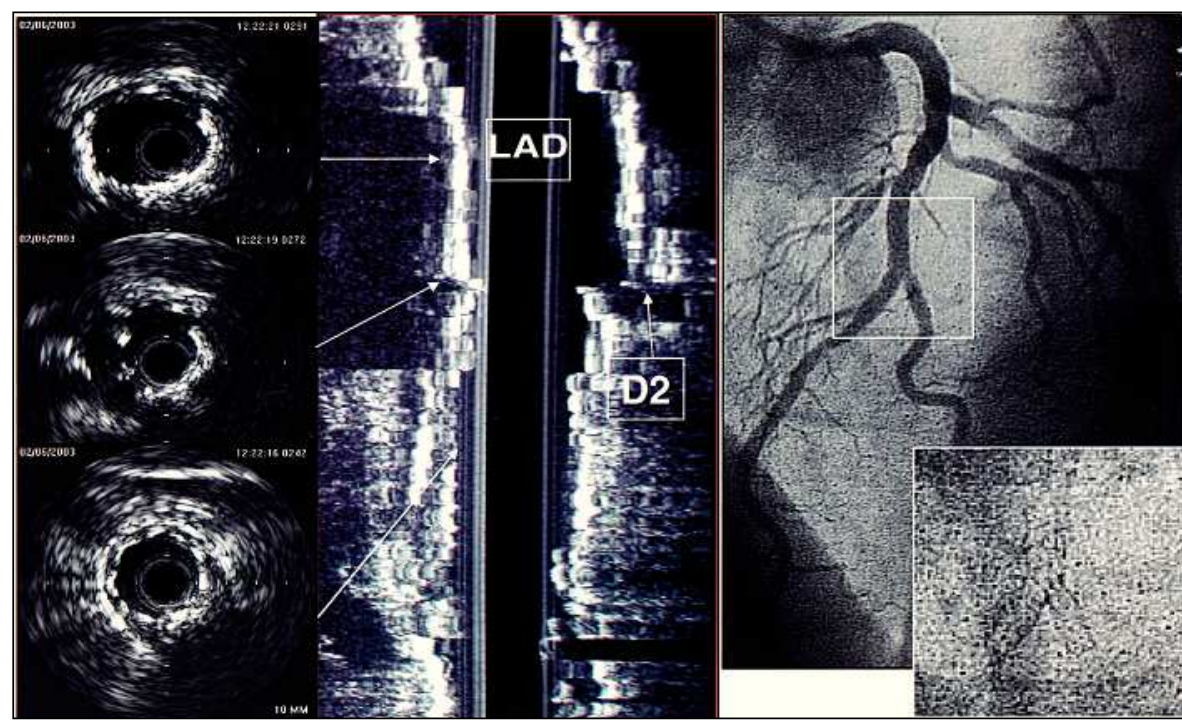
TABLE 5. Influence of Side Branch Type of Treatment on 6-Month Results*

\begin{tabular}{|c|c|c|c|}
\hline & $\begin{array}{c}\text { SB Balloon, } \\
(\mathrm{n}=39)\end{array}$ & $\begin{array}{l}\text { SB Stenting, } \\
(\mathrm{n}=16)\end{array}$ & $P$ \\
\hline \multicolumn{4}{|l|}{ Proximal reference } \\
\hline EEL area, $\mathrm{mm}^{2}$ & $18.2 \pm 6.6$ & $16.4 \pm 8$ & NS \\
\hline Lumen area, mm² & $9.5 \pm 5.0$ & $10.4 \pm 5$ & NS \\
\hline \multicolumn{4}{|l|}{ Proximal edge } \\
\hline EEL area & $19.1 \pm 6.2$ & $20.1 \pm 6$ & NS \\
\hline Lumen area & $8.2 \pm 3.7$ & $8.2 \pm 4$ & NS \\
\hline \multicolumn{4}{|c|}{ Maximal lumen diameter } \\
\hline EEL area, $\mathrm{mm}^{2}$ & $18.7 \pm 5.0$ & $18.2 \pm 4.4$ & NS \\
\hline Stent area, mm² & $7.0 \pm 1.8$ & $7.3 \pm 1.8$ & NS \\
\hline Lumen area, mm² & $6.6 \pm 1.8$ & $6.5 \pm 1.7$ & NS \\
\hline \multicolumn{4}{|c|}{ Minimal lumen diameter } \\
\hline $\mathrm{EEL}$ area, $\mathrm{mm}^{2}$ & $15.2 \pm 5.5$ & $16.7 \pm 5.1$ & NS \\
\hline Stent area, $\mathrm{mm}^{2}$ & $5.1 \pm 1.5$ & $4.6 \pm 1.2$ & NS \\
\hline Lumen area, mm² & $4.7 \pm 1.4$ & $4.2 \pm 0.9$ & NS \\
\hline \multicolumn{4}{|c|}{ Under side branch origin } \\
\hline $\mathrm{EEL}$ area, $\mathrm{mm}^{2}$ & $16.0 \pm 3.7$ & $17.8 \pm 5.1$ & NS \\
\hline Stent area, $\mathrm{mm}^{2}$ & $5.7 \pm 1.5$ & $5.4 \pm 0.9$ & NS \\
\hline Lumen area, mm² & $5.3 \pm 1.4$ & $4.8 \pm 0.9$ & NS \\
\hline \multicolumn{4}{|l|}{ Distal edge } \\
\hline EEL area, $\mathrm{mm}^{2}$ & $12.8 \pm 5.2$ & $12.3 \pm 5.9$ & NS \\
\hline Lumen area, $\mathrm{mm}^{2}$ & $6.7 \pm 2.7$ & $5.4 \pm 1.8$ & NS \\
\hline \multicolumn{4}{|l|}{ Distal reference } \\
\hline EEL area, $\mathrm{mm}^{2}$ & $11.9 \pm 5.4$ & $10.0 \pm 4.6$ & NS \\
\hline Lumen area, $\mathrm{mm}^{2}$ & $6.4 \pm 2.5$ & $6.0 \pm 2.4$ & NS \\
\hline
\end{tabular}

${ }^{*}$ EEL indicates external elastic laminae; SB, side branch.

Another interesting point to be discussed is whether or not the procedure should be completed with kissing balloon inflation. Although it has been systematically recommended during the bare-stent era, ${ }^{14}$ there were no studies that demonstrated a significant reduction in restenosis or late events after
TABLE 6: Influence of Geographic Miss on 6-Month IVUS Results

\begin{tabular}{|c|c|c|c|}
\hline \multirow[b]{2}{*}{ Lumen Area, mm² } & \multicolumn{2}{|c|}{ Proximal } & \multirow[b]{2}{*}{$P$} \\
\hline & Yes $(n=9)$ & No $(n=46)$ & \\
\hline Proximal reference & $9.9 \pm 2.4$ & $9.6 \pm 4.7$ & NS \\
\hline Proximal edge & $8.3 \pm 3.0$ & $8.1 \pm 3.9$ & NS \\
\hline Minimal lumen & $4.8 \pm 1.3$ & $4.4 \pm 1.1$ & NS \\
\hline \multicolumn{4}{|l|}{$\mathrm{EEL}$ area, $\mathrm{mm}^{2}$} \\
\hline Proximal reference & $15.6 \pm 6.3$ & $18.1 \pm 6.6$ & NS \\
\hline Proximal edge & $18.9 \pm 5.5$ & $18.7 \pm 6.6$ & NS \\
\hline \multirow[t]{2}{*}{ Minimal lumen } & $13.2 \pm 5.6$ & $16.0 \pm 5.5$ & ns \\
\hline & \multicolumn{2}{|c|}{ Distal } & \\
\hline Lumen Area, mm² & Yes $(n=16)$ & No $(n=39)$ & $P$ \\
\hline Distal reference & $5.6 \pm 2.1$ & $6.3 \pm 2.2$ & NS \\
\hline Distal edge & $6.1 \pm 2.8$ & $6.4 \pm 2.1$ & NS \\
\hline Minimal lumen & $3.7 \pm 0.7$ & $4.8 \pm 1.2$ & NS \\
\hline \multicolumn{4}{|l|}{ EEL area, mm² } \\
\hline Distal reference & $11.1 \pm 5.8$ & $11.1 \pm 4.5$ & NS \\
\hline Distal edge & $11.6 \pm 6.3$ & $12.6 \pm 4.6$ & NS \\
\hline Minimal lumen & $13.0 \pm 5.2$ & $16.6 \pm 5.4$ & NS \\
\hline
\end{tabular}

${ }^{\star}$ EEL indicates external elastic laminae.

final kissing inflation. ${ }^{15}$ In the current drug-eluting stent era the need for final kissing inflation has again emerged, and authors practising crush stenting have recommended the systematic use of this approach given the improved late outcome in patients with kissing balloon. ${ }^{16-18}$ However, we think that recommendations for crushing are not applicable for provisional or T stenting. After parent vessel stenting, the series of crushing techniques compare kissing inflation vs no side branch post dilation; in contrast, we compare side branch post dilation sequentially or

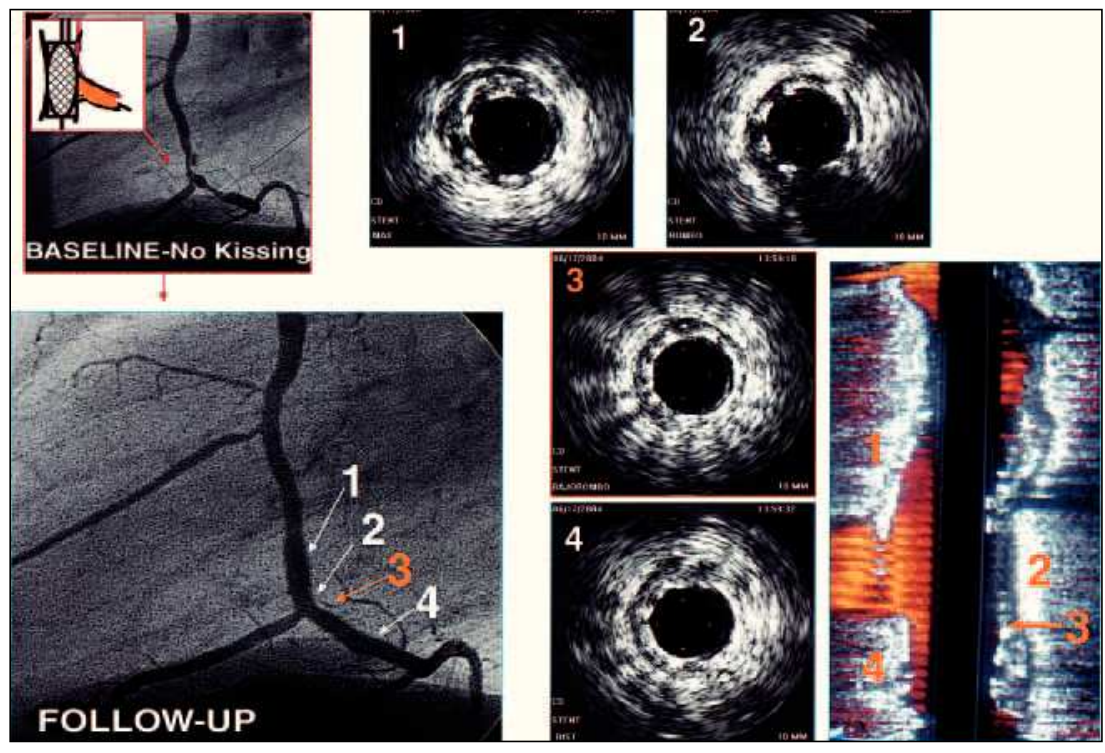

Figure 6. Example of a patient with a bifurcated lesion at the right coronary artery. The main vessel stent maintains homogeneous geometry after side branch dilation, and no deformation can be observed despite the absence of kissing balloon inflation. 1 . Proximal stent. 2. At the level of the side branch. 3. Immediately after side branch origin. 4. Distal stent. Right panel: Iongitudinal reconstruction of the stented bifurcation. 
simultaneously with the main vessel (kissing). This means that in crush-treated patients, the group with no kissing dilation did not undergo side branch post dilation. This factor may possibly account for an increase in restenosis rates at the side branch origin. ${ }^{16-18}$

Our findings are not applicable to the treatment of bifurcation lesions with bare metal stents or other drugeluting stents with higher late loss rates than RES. In these cases, a lower stent area after the procedure may be responsible for restenosis if moderate neointimal proliferation occurs.

\section{Dilation Beyond Stent Limits and Border Restenosis}

Restenosis in the segments adjacent to the proximal and distal edge of the stent has been an additional concern when radioactive or drug eluting-stents have been used. ${ }^{19,20}$ In the SIRIUS trial, edge restenosis occurred in $5.8 \%$ of the patients. ${ }^{20}$ Avoiding balloon dilation outside the stent limits seems to be a reasonable strategy, however, the influence of this maneuver on late IVUS border appearance has not yet been studied. Our study shows a nearly identical lumen area at the proximal and distal stent border in patients with or without geographic miss. On the other hand, none of our IVUS re-evaluated patients developed restenosis at stent borders. So, RES appears to have a protective effect against edge restenosis in patients with or without balloon dilation beyond the stent limits.

\section{Study Limitations}

The sample size may be small and, consequently, insufficient to reveal small statically significant differences between groups. The lack of randomization in the technique (kissing balloon or geographic miss) may lend bias to the study results, since the decision to use one strategy or the other was at the discretion of the operator. Finally, the absence of immediate IVUS study may make our findings more difficult to interpret.

\section{Conclusions}

Six month IVUS studies in patients treated with RES showed some degree of stent underexpansion under the SB origin after provisional or $\mathrm{T}$ stenting of the bifurcation lesion. This minor stent deformity was not prevented by kissing balloon inflation or by the type of SB treatment and had no significant impact on restenosis rates. IVUS border measurements are similar in patients with or without balloon inflation beyond the non-stented segment (geographic miss).

\section{REFERENCES}

1. Ormiston JA, Webster MW, Ruygrok PN, Stewart JT, White HD, Scott DS. Stent deformation following simulated side-branch dilatation comparison of five stent designs. Catheter Cardiovasc Interv. 1999;47:258-64

2. Lefévre T, Louvard Y, Morice MC, Dumas P, Loubeyre C, Benslimane A. Stenting of bifurcation lesions: classification, treatments, and results. Catheter Cardiovasc Interv. 2000;49: 274-83.

3. Ormiston JA, Currie E, Webster MW, Kay P, Ruygrok PN, Stewart JT. Drug-eluting stents for coronary bifurcations: Insights into the crush technique. Catheter Cardiovasc Interv. 2004;63: 332-6.

4. Pan M, Suárez de Lezo J, Medina A, Romero M, Segura J, Ramirez A, et al. A Stepwise strategy for the stent treatment of bifurcated coronary lesions. Catheter Cardiovasc Interv. 2002;55: 50-7.

5. Pan M, Suárez de Lezo J, Medina A, Romero M, Segura J, Pavlovic DJ, et al. Rapamycin-eluting stents for the treatment of bifurcated coronary lesions: A randomized comparison of a simple versus complex strategy. Am Heart J. 2004;148:857-64.

6. Suárez de Lezo JS, Medina A, Pan M, Delgado A, Segura J, Pavlovic D, et al. Rapamycin-eluting stents for the treatment of unprotected left main coronary disease. Am Heart J. 2004;148:4815.

7. Degertekin M, Serruys P, Foley D, Tanabe K, Regar E, Vos J, et al. Persistent inhibition of neointimal hyperplasia sfter sirolimuseluting stent implantation. Long-term (up to 2 years) clinical angiographic, and intravascular ultrasound follow-up. Circulation. 2002;106:1610-3

8. Sousa E, Costa M, Sousa A, Abizaid A, Seixas A, Abizaid A, et al. Two-year angiographic and intravascular ultrasound follow-up after implantation of sirolimus-eluting stents in human coronary arteries. Circulation. 2003;107:381-3.

9. Degertekin M, Lemos P, Lee Ch, Tanabe K, Sousa E, Abizaid A, et al. Intravascular ultrasound evaluation after sirolimus eluting stent implantation for de novo and in-stent restenosis lesions. Eur Heart J. 2004;25:32-8.

10. Serruys P, Degertekin M, Tanabe K, Russell M, Guagliumi G, Webb J, et al for the TAXUS II Study group. Vascular responses at proximal and distal edges of paclitaxel-eluting stents: serial intravascular ultrasound analysis from the TAXUS II trial. Circulation. 2004;109:627-33.

11. López-Palop R, Pinar E, Lozano I, Carrillo P, Cortés R, Saura D, et al. Comparación de parámetros de expansión de stents implantados con técnica convencional o directa. Estudio aleatorizado con ultrasonidos intracoronarios. Rev Esp Cardiol. 2004;57:40311.

12. Fujii K, Mintz G, Kobayashi Y, Carlier S, Takebayashi H, Yasuda $\mathrm{T}$, et al. Contribution of stent underexpansion to recurrence after sirolimus-eluting stent implantation for in-stent reestenosis. Circulation. 2004;109:1085-8.

13. Colombo A, Moses JW, Morice MC, Holmes LJ, Spanos V, Louvard Y, et al. Randomized study to evaluate sirolimus-eluting stents implanted at coronary bifurcation lesions. Circulation. 2004;109:1244-9.

14. Louvard Y, Lefévre T, Morice MC. Percutaneous coronary intervention for bifurcation coronary disease. Heart. 2004;90:713-22.

15. Brueck M, Scheinert D, Flachskampf FA, Daniel WG, Ludwig J. Sequential vs. kissing balloon angioplasty for stenting of bifurcation coronary lesions. Catheter Cardiovasc Interv. 2002;55:461-6.

16. Hoye A, van Mieghem C, Ong AT, Aoki J, Valgimigli M, Rodriguez $\mathrm{G}$, et al. Clinical and angiographic outcomes following crush bifurcation stenting with drug-eluting stents: low target lesion revascularization rates but high rate of side-branch restenosis in the absence of kissing balloon after dilatation (abstract). Circulation. 2004;110:757. 
Pan M, et al. Intravascular Ultrasound Evaluation of Rapamycin-Eluting Stents in Bifurcation Lesions

17. Moussa I, Leon MB, Lansky A, Lasic Z, Stone GW, Trubelja N, et al. A prospective registry to evaluate sirolimus-eluting stents implanted at coronary bifurcation lesions using The "Crush Technique" [abstract]. Circulation. 2004;110:649.

18. Sawhney N, Damani S, Price MJ, Madrid A, Kao J, Schatz RA, et al. Treatment of bifurcation lesions with sirolimus eluting stents using the "Crush" and "V" techniques. procedural "Crush" and "V" techniques. Procedural and clinical outcomes [abstract] Circulation. 2004;110:649.
19. Albiero R, Nishida T, Adamian M, Amato A, Vaghetti M, Corvaja $\mathrm{N}$, et al. Edge restenosis after implantation of high activity 32P radioactive beta-emitting stents. Circulation. 2000;101: 2454-7.

20. Moses JW, Leon MB, Popma JJ, Fitzgerald PJ, Holmes DR, O'Shaughnessy $\mathrm{C}$, et al SIRIUS Investigators. Sirolimuseluting stents versus standard stents in patients with stenosis in a native coronary artery. N Engl J Med. 2003;349:131523 . 